\title{
Diet quality and markers of endothelial function: the CARDIA study
}

\author{
Femke PC Sijtsma ${ }^{1,2}$, Katie A Meyer ${ }^{3}$, Lyn M Steffen ${ }^{1}$, Linda Van Horn ${ }^{4}$, James M Shikany ${ }^{5}$, \\ Andrew O Odegaard ${ }^{1}$, Myron D Gross ${ }^{6}$, Daan Kromhout ${ }^{2}$, and David R Jacobs Jr $^{1,7}$
}

\begin{abstract}
${ }^{1}$ The Division of Epidemiology and Community Health, School of Public Health, University of Minnesota, Minneapolis, Minnesota ${ }^{2}$ The Division of Human Nutrition, Wageningen University, Wageningen, The Netherlands ${ }^{3}$ Department of Nutrition, University of North Carolina, Chapel Hill, North Carolina ${ }^{4}$ Department of Preventive Medicine, Feinberg School of Medicine, Northwestern University, Chicago, Illinois ${ }^{5}$ Division of Preventive Medicine, University of Alabama at Birmingham, Birmingham, Alabama ${ }^{6}$ Department of Laboratory Medicine and Pathology, University of Minnesota, Minneapolis, Minnesota ${ }^{7}$ The Department of Nutrition, University of Oslo, Oslo, Norway
\end{abstract}

\begin{abstract}
Background: Dietary patterns are associated cross-sectionally with cellular adhesion molecules (CAMs).

Objective: We studied prospective associations of three dietary patterns with CAMs.

Design: In the Coronary Artery Risk Development in Young Adults (CARDIA) study, diet was assessed at years 0 (1985-86) and 7 (1992-93) examinations. Four circulating CAMs (E-selectin, P-selectin, soluble intercellular adhesion molecule 1 (sICAM-1), and vascular cellular adhesion molecule (VCAM)) were assayed at years 7 and 15 (2000-01). We created one index score "A Priori Diet Quality Score" and derived dietary patterns using principal components analysis (PCA). Multivariable linear regression models predicted year 15 CAMs from averaged (year 0/7) dietary patterns.
\end{abstract}

Results: The A Priori Diet Quality Score rated 46 food groups beneficial, neutral or adverse based on hypothesized health effects. We derived two PCA dietary patterns: "fruit and vegetables (FV)" (high intakes of fruit, vegetables, and whole grains) and "meat" (high intakes of red meat, refined grain, and butter). All dietary patterns were related to E-selectin and sICAM-1. P-selectin was not related to the FV dietary pattern. VCAM was only related to the A Priori Diet Quality Score. Strongest associations were for the meat dietary pattern with E-selectin (effect size $28 \%$ of an $\mathrm{SD}(+3.9 / 13.7 \mathrm{ng} / \mathrm{mL})$ and P-selectin (effect size $37 \%$ of an $\mathrm{SD}(+4.1 / 11.2 \mathrm{ng} / \mathrm{mL}$ ) and the $A$

\footnotetext{
(C) 2014 Elsevier B.V. All rights reserved

Corresponding Author and reprint requests: Femke P.C. Sijtsma, Wageningen University, Division of Human Nutrition, P.O. Box 8129, 6700 EV Wageningen, Room 116, Biotechnion Phone: +31 317 481 484, femke.sijtsma@wur.nl.

Publisher's Disclaimer: This is a PDF file of an unedited manuscript that has been accepted for publication. As a service to our customers we are providing this early version of the manuscript. The manuscript will undergo copyediting, typesetting, and review of the resulting proof before it is published in its final citable form. Please note that during the production process errors may be discovered which could affect the content, and all legal disclaimers that apply to the journal pertain.
} 
Priori Diet Quality Score with sICAM-1 (effect size 34\% of an SD $(-15.1 / 44.7 \mathrm{ng} / \mathrm{mL}$ ) and VCAM (effect size of $26 \%$ of an SD $(-45.1 / 170.3 \mathrm{ng} / \mathrm{mL})$.

Conclusion: This prospective analysis suggests that dietary patterns are associated with CAMs.

\section{Keywords}

Cohort; Epidemiology; Diet; Endothelial function; Cellular Adhesion Molecules (CAMs)

\section{Introduction}

Endothelial dysfunction occurs early in atherosclerotic development (1). The cellular adhesion molecules (CAMs) E-selectin, P-selectin, intercellular adhesion molecule-1 (ICAM-1), and vascular cellular adhesion molecule (VCAM), are expressed by inflamed endothelium and participate in recruitment and adhesion of leucocytes to endothelial cells (2). Higher circulating concentrations of these CAMs indicate endothelial dysfunction, promote atherosclerosis, and associate with subclinical cardiovascular disease (3). Diet influencing endothelial function may be a mechanism by which dietary quality affects the development of cardiovascular disease.

Clinical and experimental studies suggested that dietary n-3 fatty acids, antioxidant vitamins, folic acid, and L-arginine have beneficial effects on endothelial function, likely through multiple, complex mechanisms. Examples are inhibition of monocyte adhesion and platelet activation, increased nitric-oxide production and improvement of vasodilation, and blockage of lipid oxidation (4). Randomized cross-over trials showed that Mediterraneanstyle diets improved endothelial function $(5,6)$. Cross-sectional studies found inverse associations between principal components analysis (PCA)-derived dietary patterns and markers of endothelial function in women (7) and in ethnically diverse men and women (8). Some, but not all, cross-sectional associations of different prudent dietary patterns were inverse with endothelial function (9). One longitudinal study investigated consumption of food groups and markers of endothelial function, but overall dietary pattern was not assessed (10). Associations of dietary patterns with markers of endothelial function have not been investigated in prospective studies.

We hypothesized that the A Priori Diet Quality Score and the FV dietary pattern with high loadings on fruit and vegetables is inversely related to E-selectin, P-selectin, sICAM-1, and VCAM. Similarly, we hypothesize that the meat dietary pattern with high loadings of meat, butter, and refined grains is positively related to these CAMs.

\section{Methods}

\section{Study sample}

The Coronary Artery Risk Development in Young Adults (CARDIA) Study is a multicenter, longitudinal investigation of the evolution of coronary heart disease risk starting in young adulthood (11). CARDIA recruited a population-based sample of 5115 black and white men and women aged 18-30 years in Birmingham, AL; Chicago, IL; Minneapolis, MN; and Oakland, CA. Recruitment achieved roughly equal proportions of blacks (51.5\%) and whites 
(48.5\%), men (45.5\%) and women (54.5\%), ages 18-24 y (44.9\%) and 25-30 y (55.1\%), and with shigh school education $(39.7 \%)$ or $>$ high school education $(60.3 \%)$. For the present study, we used dietary data collected at baseline (1985-86) and after 7 years of follow-up (1992-93). The response rates were $81 \%$ at year 7 and $74 \%$ at year 15 (2000-01). Young Adult Longitudinal Trends in Antioxidants (YALTA) and Circulating CAMs and the Vasculature are CARDIA ancillary studies in which the CAMs E-selectin, P-selectin, sICAM-1, and VCAM were measured in year 7 and year 15. Institutional Review Board approval and informed consent were obtained at each study center at every examination. Participants who had missing dietary data $(n=4$ at year 0 and $n=143$ at year 7$)$, or implausibly high or low energy intake (<800 or $>8000 \mathrm{kcal} /$ day for men, $<600$ or $>6000$ $\mathrm{kcal} /$ day for women $)(\mathrm{n}=128$ at year 0 and $\mathrm{n}=94$ at years 7$)$ were excluded from analysis. Accounting for analysis-specific exclusions due to missing data for relevant exposures or covariates, we included 2789 participants for the prospective analysis of year 15 values of Eselectin and the average of year 0 and 7 dietary patterns, 2947 for P-selectin, 2911 for sICAM-1, and 2998 for VCAM.

\section{Blood collection and measurements of biomarkers}

Overnight fasting blood samples were processed within $90 \mathrm{~min}$ of blood collection and stored at $-70^{\circ} \mathrm{C}$ until shipped on dry ice to a central laboratory. Participants were asked to fast $\geq 12$ hours and to avoid heavy physical activity and smoking for 2 hours before examination. CAMs were assayed at the Molecular Epidemiology and Biomarker Research Laboratory in the University of Minnesota with sandwich ELISA methods from R \& D Systems (E-selectin Cat No: DSLE00, P-selectin Cat No: BBE6, sICAM-1 Cat. No. DCD540 (year 7) and DY720 (year 15), and VCAM Cat No. DVC00). Serum (E-selectin) and plasma (P-selectin) samples from year 7 and 15 exams were diluted 10- and 6-fold, respectively. The within plus between day coefficients of variation $(\mathrm{CV})$ were 7.7 and $10.5 \%$, respectively. The E-selectin measurements for years 7 and 15 were performed over a period of several months, and no assay drift was evident during this time.

Serum (sICAM-1) samples from year 7 and 15 exams were diluted 10- and 400-fold and plasma (VCAM) samples 21-fold. The within plus between day CVs were $<10 \%$ (both sICAM-1 assays) and 9.0\% (VCAM). All VCAM analyses of the year 7 and 15 samples were performed over a few months in 2010, and no assay drift was detected during this time. To account for assay drift (P-selectin), assay change and the prevalence of the single nucleotide polymorphism rs5491 T-allele (sICAM-1), P-selectin and sICAM-1 were calibrated (details in the online supplemental material).

\section{Other measurements}

Standard questionnaires were used to obtain self-reported demographic and behavioral information across CARDIA examinations. Information on sex, race, date of birth, education, and cigarette smoking was collected by structured interview or self-administered questionnaire at each examination. Educational status was quantified as the maximum (at any examination) reported number of years of schooling completed. Self-reported smoking status was classified as never, former, or current . A physical activity score was derived from the CARDIA Physical Activity History. The total exercise score was in exercise units 
(a sum across 13 activities of frequency times intensity). Height and weight were measured at each examination and recorded to the nearest $0.5 \mathrm{~cm}$ and $0.2 \mathrm{~kg}$, respectively. Body mass index (BMI) was calculated as weight $(\mathrm{kg}) /$ height $^{2}(\mathrm{~m})$.

\section{Dietary assessment and creation of dietary pattern scores}

Diet assessment and the procedure for the creation of dietary patterns were described in detail elsewhere $(12,13)$. In summary diet was assessed at years 0 and 7 by intervieweradministered CARDIA Diet History (14).

Foods were assigned to one of 166 food groups using the food grouping system devised by the University of Minnesota Nutrition Coordinating Center (NCC). We further collapsed these food groups into 46 food groups based on similar nutrient characteristics and comparability to food groups defined in previous studies (15-17).

The A Priori Diet Quality Score was created by classifying 46 foods groups as beneficial $(\mathrm{n}=20)$, adverse $(\mathrm{n}=13)$, or neutral $(\mathrm{n}=13)$ in terms of hypothesized health effects(15-17). The $a$ priori assignment for each of the 46 food groups (beneficial="+", adverse="-“, neutral $=$ "0") was described in detail elsewhere $(12,13)$ and can be found in Supplemental Table 2. The A Priori Diet Quality Score was the sum of category scores 0 to 4 for the beneficial items plus scores in reverse order (4 to 0 ) for adverse foods. Food groups that were considered neutral did not contribute to the overall A Priori Diet Quality Score. The theoretical maximum score was 132 , higher scores indicating a healthier dietary pattern.

We used PCA with orthogonal rotation to derive uncorrelated dietary patterns and determine factor loadings for each of the 46 food groups. We selected the 2 principal components that explained the most dietary variance (Supplemental Table 2). We refer to these 2 factors as "meat dietary pattern" and "fruit and vegetable (FV) dietary pattern" to reflect their relatively high loadings of red meat (as well as refined grain and butter) or fruits and vegetables (as well as whole grains and lean fish), respectively. Factor loadings were generally consistent across years; factor loadings $<0.20$ were suppressed in Supplemental Table 2.

\section{Statistics}

Unadjusted means of participant characteristics were calculated by quintiles of A Priori Diet Quality Score and the two dietary patterns. Multivariable adjusted linear regression models assessed associations of dietary patterns (averaged year 0 and 7 , using 1 exam if the other was missing), each divided into consumption quintiles, to predict E-selectin, P-selectin, sICAM-1, and VCAM prospectively for CAMs at year 15. Parallel cross-sectional analyses for CAMs at year 7 were examined in sensitivity analyses, as was ability to predict change in CAMs between year 7 and year 15 .

Separate regression analyses were conducted for each dietary pattern. Tests for trend used multivariable linear regression models with continuous dietary pattern scores. We studied different levels of adjustment. A minimal model (model 1) included sex (male, female), race (black, white), study center (Birmingham, Chicago, Minneapolis, Oakland), year 0 age (continuous), and total energy (continuous). The model was further adjusted for smoking 
status (current/ never/former), educational attainment, and physical activity (model 2). To investigate BMI and waist circumference as potential intermediaries between dietary patterns and endothelial function, we included these variables in a subsequent model (model $3)$.

We used the PC version (9.2) of the Statistical Analysis System (SAS, Cary, NC).

\section{Results}

\section{Baseline characteristics}

Age, white race, and educational attainment were positively associated with the A Priori Diet Quality Score and the FV pattern and negatively related to the meat dietary pattern (Table 1). Total energy decreased across quintiles of the A Priori Diet Quality Score and increased both in the meat and in the FV dietary patterns. People at higher levels of the $A$ Priori Diet Quality Score and FV dietary pattern were less likely to smoke and had a lower waist circumference; the reverse was true for people scoring high on the meat dietary pattern. BMI decreased across quintiles of the A Priori Diet Quality Score and FV dietary pattern and was not significantly associated with the meat dietary pattern. Physical activity increased across quintiles of all three dietary patterns.

Unadjusted concentrations of E-selectin, P-selectin, and sICAM-1 were all lower at higher values of the A Priori Diet Quality Score and the FV pattern and higher at higher values of the meat dietary pattern. VCAM showed a reverse pattern, being positively related to the $A$ Priori Diet Quality Score and the FV pattern, but inversely related to the meat pattern.

Tracking correlation coefficients between year 7 and 15 were 0.57 for P-selectin, 0.77 for Eselectin, 0.59 for sICAM-1, and 0.70 for VCAM. Correlations were 0.39 between E-selectin and P-selectin , 0.44 between E-selectin and sICAM-1, 0.26 between P-selectin and sICAM, and lower than 0.2 for all other combinations.

\section{Dietary patterns and cellular adhesion molecules}

In each multivariable model (Table 2), all three dietary patterns were associated with Eselectin. A strong association was seen with the meat dietary pattern ( $\left.\mathrm{p}_{\text {trend }}<0.001\right)$. In model 2, the mean E-selectin was $3.9 \mathrm{ng} / \mathrm{mL}$ higher in the highest meat dietary pattern quintile compared to the lowest. This was an effect size of $27 \%(3.9 / 13.7 \mathrm{ng} / \mathrm{mL})$ of an SD.

P-selectin was inversely associated with the A Priori Diet Quality Score $\left(\mathrm{p}_{\text {trend }} 0.004\right)$ and positively with the meat dietary pattern ( $\left.\mathrm{p}_{\text {trend }} 0.02\right)$. The strongest association between Pselectin and diet was with the meat dietary pattern. The mean P-selectin was $4.1 \mathrm{ng} / \mathrm{mL}$ higher in the highest compared to the lowest meat dietary pattern quintile. This was an effect size of $37 \%(4.1 / 11.2 \mathrm{ng} / \mathrm{mL})$ of an SD. P-selectin was not significantly associated with the FV dietary pattern.

All three dietary patterns were associated with sICAM-1. The A Priori Diet Quality Score was strongly inversely associated with sICAM-1( $\left.\mathrm{p}_{\text {trend }}<0.001\right)$. The mean sICAM-1 was 
$15.1 \mathrm{ng} / \mathrm{mL}$ lower in the highest vs. the lowest $A$ Priori Diet Quality Score quintile. This was an effect size of $34 \%$ of an SD $(15.1 / 44.7 \mathrm{ng} / \mathrm{mL})$ for sICAM-1.

VCAM was inversely associated with the A Priori Diet Quality Score ( $\mathrm{p}_{\text {trend }} 0.006$ ). The mean VCAM was $45.1 \mathrm{ng} / \mathrm{mL}$ lower in the highest vs. the lowest $A$ Priori Diet Quality Score quintile. This was an effect size of $26 \%$ of an SD $(45.1 / 170.3 \mathrm{ng} / \mathrm{mL})$ for VCAM.

Further adjustment for BMI and waist (model 3) gave qualitatively similar results. Adjustment for plasma lipids (cholesterol, high-density lipoprotein and triglycerides) and measures of glucose metabolism (HOMA, glucose and insulin) did not substantively change the estimates shown in Model 3 of the association of diet with any of the CAMs (data not shown).

In a secondary analysis we examined associations of dietary patterns and CAMs at year 7 (Supplemental table 2). Cross-sectional associations were generally weaker than the longitudinal analysis presented in Table 3 and in some cases did not reach statistical significance. Cross-sectional associations of dietary patterns formed exclusively from year 7 data with the CAMs were similar to findings in Supplementary Table 1 for the A Priori Diet Quality Score, but were somewhat weaker for the two principal components patterns (data not shown).

Because the associations with the CAMs at year 15 tended to be stronger than the corresponding associations with CAMs at year 7, we looked at predicting evolution of the CAMs, using the full adjustment of model 3. Dependent variables were the year 15 CAM concentrations, covarying the year 7 CAM concentrations. For the A Priori Diet Quality Score, these associations were in the expected direction, that is better diet predicted less increase in each CAM, but $\mathrm{p}$-values were generally not significant $(\mathrm{E}$-selectin $\mathrm{n}=1941, \mathrm{t}=$ $-1.83, \mathrm{p}=0.07 ;$ P-selectin $\mathrm{n}=2545, \mathrm{t}=-1.56, \mathrm{p}=0.12$; sICAM-1: $\mathrm{n}=1698, \mathrm{t}=-0.66, \mathrm{p}=$ $0.51 ; \operatorname{VCAM~} \mathrm{n}=2580, \mathrm{t}=-2.04, \mathrm{p}=0.04)$.

\section{Discussion}

We showed that CAMs are related longitudinally to dietary patterns. The A Priori Diet Quality Score was inversely related to E-selectin, P-selectin, sICAM-1, and VCAM. Using PCA, we identified an FV and a meat dietary pattern, which were, respectively, positively and inversely correlated with the A Priori Diet Quality Score. The FV dietary pattern was inversely associated with E-selectin and sICAM-1 but not with P-selectin and VCAM. The meat dietary pattern was positively associated with E-selectin, P-selectin, and sICAM-1, but not with VCAM. Although CAMs are related to adiposity, blood lipids, and insulin resistance, adjustment for the year 7 values of these variables did not suggest mediation of the diet-CAM associations.

Previous studies investigated cross-sectional associations of PCA-derived dietary patterns with CAMs. Nettleton et al. found that sICAM-1 was inversely associated with a "whole grain and fruit" pattern and positively related to a "bean, tomatoes and refined grain" pattern. "Fats and processed meats" and "vegetables and fish" patterns were not associated with sICAM-1, and E-selectin was not associated with any of the dietary patterns (8). 
Similarly, Lopez-Garcia found that E-selectin, sICAM-1, and VCAM were positively associated with a PCA-derived Western diet. A prudent diet was only inversely associated with E-selectin (7). Fung et al. compared several diet quality scores and found E-selectin was inversely associated with all diet quality scores. sICAM-1 was inversely associated with the Alternate Healthy Eating Index (AHEI)(18) and Alternate Mediterranean Diet Index (aMED), and VCAM was only inversely associated to aMED (9).

This suggests that including different nutrients or food groups or different weightings of food groups included in the dietary patterns may affect the strength of the diet pattern associations with circulating markers of endothelial dysfunction. Diet quality scores are a stable characteristic compared to food groups or nutrients and are therefore a useful approach to study relations with CAMs. Although the findings are robust and in expected directions, there are differences in the strength of the associations of the CAMs and the three dietary patterns. All three dietary patterns were created using the same food groups, but the weightings of the food groups differ between the two methods. The PCA approach weights each food group, normalized to its standard deviation. The A Priori Diet Quality Score first sorts food groups into beneficial, adverse, or neutral, then weights them by their quintile position in the intake distribution. The A Priori Diet Quality Score emphasized more beneficial food groups $(\mathrm{n}=20)$ than adverse food groups $(\mathrm{n}=13)$. In terms of the a priori ratings of food groups as beneficial or adverse, the FV pattern emphasized the beneficial groups, whereas the meat dietary pattern emphasized the adverse food groups.

Our study sample was relatively young (mean age 32 at year 7, and 40 in year 15), and had lower concentrations of CAMs compared to previous studies (7-9), which could in part explain why our cross-sectional analysis showed weaker associations than our longitudinal associations.

CAMs have an important role in the accumulation of circulating leukocytes at sites of injury, infection, and inflammation. This accumulation of leukocytes involves several steps (known as the leukocyte adhesion cascade) and cell types including $\mathrm{T}$ and $\mathrm{B}$ cells, monocytes and macrophages, dendritic cells, and natural killer cells. In the cascade, cells undergo tethering, rolling, activation, arrest, tight adhesion, and diapedesis. Unique combinations of endothelial adhesion molecules and chemokines direct tissue-specific migration of leukocytes and control the various steps in the cascade (19-21). For example, $\mathrm{P}$ and E-selectin are involved in the tethering, rolling, and activation of leukocytes. ICAM-1 facilitates monocyte/ macrophage migration and adherence to endothelial cells. VCAM facilitates macrophage uptake into the subintimal space. Together, the CAMs form an integrated and overlapping system for the transport of leukocytes into the vascular wall and have an active role in the development of atherosclerotic plaque (22).

Our study has several strengths. First, repeated measurements of diet averaged for analysis may increase the reliability of our data. Second, because of the large CARDIA sample and extensive data we could adjust for important confounding variables. Third, our study included two primary methods to create dietary patterns. The A Priori Diet Quality Score is based on current judgment whereas the PCA patterns are based on correlations among food groups, as consumed by the participants. Fourth, repeated measurements of cellular adhesion 
molecules allowed us to investigate associations of dietary patterns with these markers both cross-sectionally and longitudinally.

Our study also has limitations. Although we accounted for many possible confounders, as in every observational study, we cannot rule out residual confounding. In conclusion, both an $a$ priori dietary score and a posteriori dietary patterns were related to endothelial function and support protective effects of a prudent dietary pattern high in fruits and vegetables and low in red meats, processed meats, and refined grains on health of the endothelium. The association of higher diet quality with biomarkers of endothelial function should be considered as a possible pathway through which diet may affect the development of cardiovascular disease.

\section{Supplementary Material}

Refer to Web version on PubMed Central for supplementary material.

\section{Acknowledgments}

Source of Funding: Supported by contracts HHSN268201300025C, HHSN268201300026C, HHSN268201300027C, HHSN268201300028C, HHSN268201300029C, and HHSN268200900041C from the National Heart, Lung, and Blood Institute, grants R01-HL-53560 (YALTA), R01 HL093077 (Circulating CAMs and the Vasculature), and T32 HL07779, and the Intramural Research Program of the National Institute on Aging.

\section{References}

1. Ross R. Atherosclerosis--an inflammatory disease. NEnglJMed. 1999; 340(2):115-26. doi: 10.1056/ NEJM199901143400207.

2. Calder PC, Ahluwalia N, Albers R, Bosco N, Bourdet-Sicard R, Haller D, Holgate ST, Jonsson LS, Latulippe ME, Marcos A, et al. A Consideration of Biomarkers to be Used for Evaluation of Inflammation in Human Nutritional Studies. Br J Nutr. 2013; 109(Suppl 1):S1-S34. doi: S0007114512005119. [PubMed: 23343744]

3. Gross MD, Bielinski SJ, Suarez-Lopez JR, Reiner AP, Bailey K, Thyagarajan B, Carr JJ, Duprez DA, Jacobs DR Jr. Circulating Soluble Intercellular Adhesion Molecule 1 (sICAM-1) and Subclinical Atherosclerosis: the Coronary Artery Risk Development in Young Adults (CARDIA) Study. ClinChem. 2011 doi: clinchem.2011.168559.

4. Brown AA, Hu FB. Dietary modulation of endothelial function: implications for cardiovascular disease. AmJClinNutr. 2001; 73(4):673-86.

5. Marin C, Ramirez R, Delgado-Lista J, Yubero-Serrano EM, Perez-Martinez P, Carracedo J, GarciaRios A, Rodriguez F, Gutierrez-Mariscal FM, Gomez P, et al. Mediterranean diet reduces endothelial damage and improves the regenerative capacity of endothelium. AmJClinNutr. 2011; 93(2):267-74. doi: ajcn.110.006866.

6. Fuentes F, Lopez-Miranda J, Perez-Martinez P, Jimenez Y, Marin C, Gomez P, Fernandez JM, Caballero J, Delgado-Lista J, Perez-Jimenez F. Chronic effects of a high-fat diet enriched with virgin olive oil and a low-fat diet enriched with alpha-linolenic acid on postprandial endothelial function in healthy men. Br J Nutr. 2008; 100(1):159-65. doi: S0007114508888708. [PubMed: 18275619]

7. Lopez-Garcia E, Schulze MB, Fung TT, Meigs JB, Rifai N, Manson JE, Hu FB. Major dietary patterns are related to plasma concentrations of markers of inflammation and endothelial dysfunction. AmJClinNutr. 2004; 80(4):1029-35. doi: 80/4/1029.

8. Nettleton JA, Steffen LM, Mayer-Davis EJ, Jenny NS, Jiang R, Herrington DM, Jacobs DR Jr. Dietary patterns are associated with biochemical markers of inflammation and endothelial activation in the Multi-Ethnic Study of Atherosclerosis (MESA). AmJClinNutr. 2006; 83(6):1369-79. doi: 83/6/1369. 
9. Fung TT, McCullough ML, Newby PK, Manson JE, Meigs JB, Rifai N, Willett WC, Hu FB. Dietquality scores and plasma concentrations of markers of inflammation and endothelial dysfunction. AmJClinNutr. 2005; 82(1):163-73. doi: 82/1/163.

10. van Bussel BC, Henry RM, Schalkwijk CG, Ferreira I, Feskens EJ, Streppel MT, Smulders YM, Twisk JW, Stehouwer CD. Fish Consumption in Healthy Adults Is Associated with Decreased Circulating Biomarkers of Endothelial Dysfunction and Inflammation during a 6-Year Follow-Up. JNutr. Sep; 2011 141(9):1719-25. doi: jn.111.139733. [PubMed: 21753064]

11. Friedman GD, Cutter GR, Donahue RP, Hughes GH, Hulley SB, Jacobs DR, Liu K, Savage PJ. CARDIA: study design, recruitment, and some characteristics of the examined subjects. Journal of clinical epidemiology. 1988; 41(11):1105-16. doi: 0895-4356(88)90080-7. [PubMed: 3204420]

12. Meyer KA, Sijtsma FPC, Nettleton JA, Steffen LM, Van Horn L, Shikany JM, Gross MD, Mursu J, Traber MG, Jacobs DR Jr. Dietary patterns are associated with plasma F(2)-isoprostanes in an observational cohort study of adults. Free Radic Biol Med. 2012 doi: S0891-5849(12)01081-7.

13. Sijtsma FP, Meyer KA, Steffen LM, Shikany JM, Van Horn L, Harnack L, Kromhout D, Jacobs DR Jr. Longitudinal trends in diet and effects of sex, race, and education on dietary quality score change: the Coronary Artery Risk Development in Young Adults study. AmJClinNutr. 2012; 95(3):580-6. doi: ajcn.111.020719.

14. McDonald A, Van Horn L, Slattery M, Hilner J, Bragg C, Caan B, Jacobs DR Jr. Liu K, Hubert H, Gernhofer N, et al. The CARDIA dietary history: development, implementation, and evaluation. J Am Diet Assoc. 1991; 91(9):1104-12. [PubMed: 1918764]

15. Jacobs DR, Sluik D, Rokling-Andersen MH, Anderssen SA, Drevon CA. Association of 1-y changes in diet pattern with cardiovascular disease risk factors and adipokines: results from the 1-y randomized Oslo Diet and Exercise Study. AmJClinNutr. 2009; 89(2):509-17. doi: ajen. 2008.26371.

16. Lockheart MS, Steffen LM, Rebnord HM, Fimreite RL, Ringstad J, Thelle DS, Pedersen JI, Jacobs DR Jr. Dietary patterns, food groups and myocardial infarction: a case-control study. Br J Nutr. 2007; 98(2):380-7. doi: 10.1017/s0007114507701654. [PubMed: 17391555]

17. Nettleton JA, Schulze MB, Jiang R, Jenny NS, Burke GL, Jacobs DR Jr. A priori-defined dietary patterns and markers of cardiovascular disease risk in the Multi-Ethnic Study of Atherosclerosis (MESA). AmJClinNutr. 2008; 88(1):185-94.

18. McCullough ML, Feskanich D, Stampfer MJ, Giovannucci EL, Rimm EB, Hu FB, Spiegelman D, Hunter DJ, Colditz GA, Willett WC. Diet quality and major chronic disease risk in men and women: moving toward improved dietary guidance. AmJClinNutr. 2002; 76(6):1261-71.

19. von Andrian UH, Mackay CR. T-cell function and migration. Two sides of the same coin. NEnglJMed. 2000; 343(14):1020-34. doi: 10.1056/NEJM200010053431407.

20. Cyster JG. Homing of antibody secreting cells. Immunol Rev. 2003; 194:48-60. doi: 041. [PubMed: 12846807]

21. Campbell DJ, Kim CH, Butcher EC. Chemokines in the systemic organization of immunity. Immunol Rev. 2003; 195:58-71. doi: 067. [PubMed: 12969310]

22. Galkina E, Ley K. Leukocyte influx in atherosclerosis. Curr Drug Targets. 2007; 8(12):1239-48. [PubMed: 18220701] 


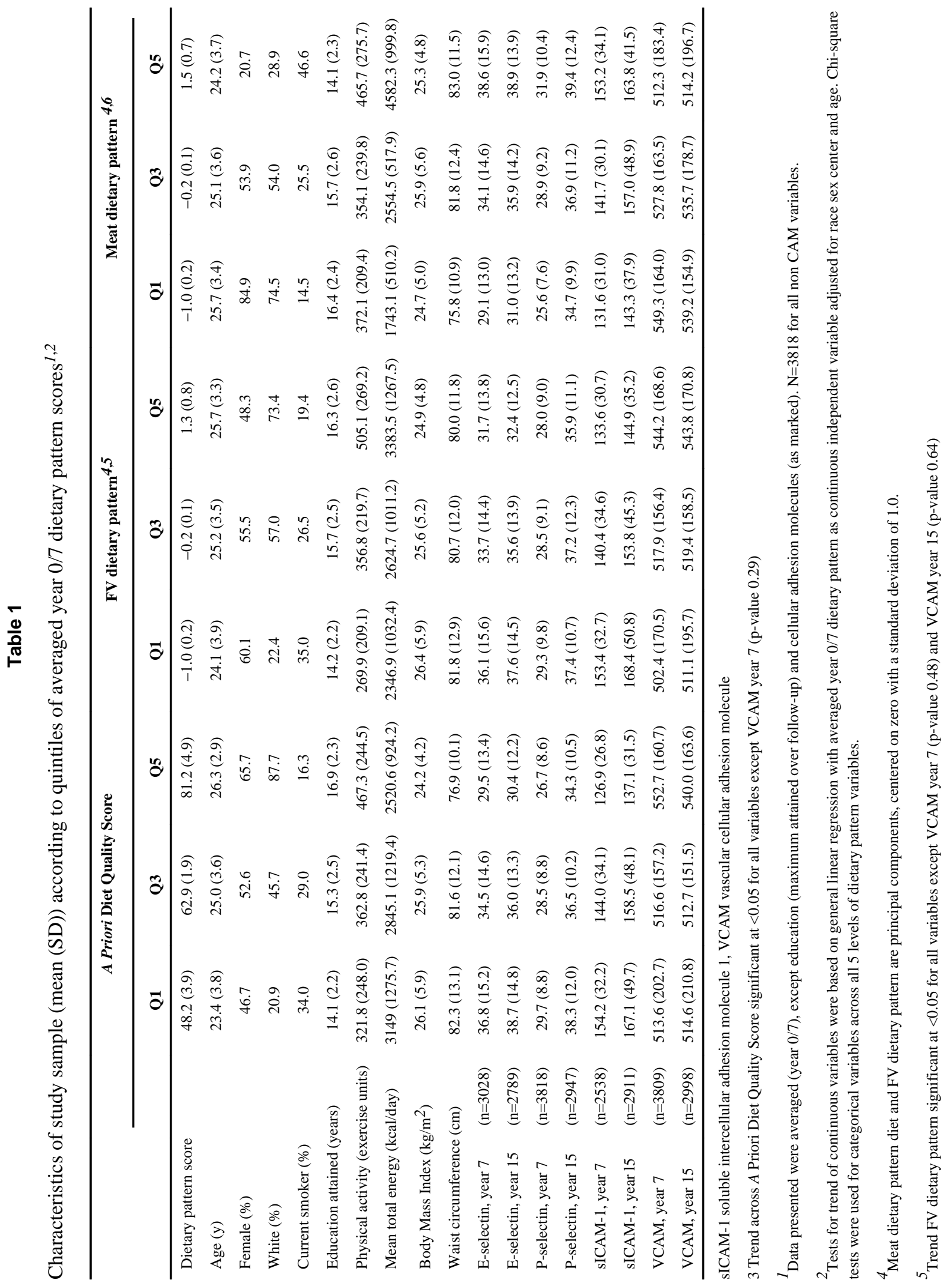


Table 2

Estimates (SE) of year 15 soluble adhesion molecules per quintile of averaged year 0/7 dietary pattern

\begin{tabular}{|c|c|c|c|c|c|c|c|}
\hline & & \multicolumn{5}{|c|}{ Quintile of Dietary Pattern Consumption } & \multirow[b]{2}{*}{ Ptrend 1} \\
\hline & & 1 & 2 & 3 & 4 & 5 & \\
\hline \multirow{16}{*}{$\begin{array}{c}\text { A Priori } \\
\text { Diet Quality } \\
\text { Score }\end{array}$} & E selectin year $15(35.1(13.7))$ & 446 & 514 & 576 & 643 & 639 & \\
\hline & model 1 & 0 & $-0.5(0.8)$ & $-1.3(0.9)$ & $-1.8(0.9)$ & $-4.2(1.0)$ & $<0.001$ \\
\hline & model 2 & 0 & $-0.3(0.8)$ & $-0.7(0.9)$ & $-0.7(0.9)$ & $-2.4(1.0)$ & 0.02 \\
\hline & model 3 & 0 & $-0.5(0.8)$ & $-0.8(0.8)$ & $-0.6(0.9)$ & $-1.8(1.0)$ & 0.08 \\
\hline & P selectin year 15 (36.8 (11.2)) & 471 & 537 & 611 & 682 & 646 & \\
\hline & model 1 & 0 & $-0.4(0.7)$ & $-2.0(0.7)$ & $-1.2(0.7)$ & $-3.4(0.8)$ & $<0.001$ \\
\hline & model 2 & 0 & $-0.3(0.7)$ & $-1.7(0.7)$ & $-0.6(0.7)$ & $-2.6(0.8)$ & 0.004 \\
\hline & model 3 & 0 & $-0.4(0.7)$ & $-1.7(0.7)$ & $-0.6(0.7)$ & $-2.4(0.8)$ & 0.009 \\
\hline & sICAM-1 year $15(154.7(44.7))$ & 464 & 531 & 603 & 674 & 639 & \\
\hline & model 1 & 0 & $-1.2(2.7)$ & $-5.6(2.7)$ & $-9.5(2.8)$ & $-21.2(3.1)$ & $<0.001$ \\
\hline & model 2 & 0 & $-0.9(2.6)$ & $-4.3(2.7)$ & $-5.9(2.8)$ & $-15.1(3.1)$ & $<0.001$ \\
\hline & model 3 & 0 & $-1.4(2.6)$ & $-4.3(2.6)$ & $-5.5(2.7)$ & $-12.9(3.1)$ & $<0.001$ \\
\hline & VCAM year 15 (525.8 (170.3)) & 417 & 541 & 618 & 657 & 665 & \\
\hline & model 1 & 0 & $-19.3(10.1)$ & $-32.4(10.1)$ & $-18.7(10.6)$ & $-45.4(11.6)$ & 0.002 \\
\hline & model 2 & 0 & $-19.4(10.2)$ & $-32.1(10.3)$ & $-18.9(11.0)$ & $-45.1(12.4)$ & 0.006 \\
\hline & model 3 & 0 & $-18.9(10.2)$ & $-31.9(10.3)$ & $-18.7(11.0)$ & $-45.5(12.4)$ & 0.005 \\
\hline \multirow{21}{*}{$\begin{array}{l}\text { FV dietary } \\
\text { pattern }\end{array}$} & E selectin year 15 & 495 & 551 & 576 & 583 & 584 & \\
\hline & model 1 & 0 & $-0.8(0.8)$ & $-0.7(0.8)$ & $-1.3(0.9)$ & $-3.5(0.9)$ & $<0.001$ \\
\hline & model 2 & 0 & $0.0(0.8)$ & $0.4(0.8)$ & $0.4(0.9)$ & $-1.3(1.0)$ & 0.03 \\
\hline & model 3 & 0 & $0.0(0.8)$ & $0.5(0.8)$ & $0.5(0.9)$ & $-1.2(1.0)$ & 0.02 \\
\hline & P selectin year 15 & 524 & 585 & 600 & 619 & 619 & \\
\hline & model 1 & 0 & $-0.4(0.7)$ & $-0.6(0.7)$ & $-1.5(0.7)$ & $-2.2(0.8)$ & 0.003 \\
\hline & model 2 & 0 & $0.1(0.7)$ & $0.1(0.7)$ & $-0.4(0.7)$ & $-0.8(0.8)$ & 0.28 \\
\hline & model 3 & 0 & $0.1(0.7)$ & $0.2(0.7)$ & $-0.3(0.7)$ & $-0.8(0.8)$ & 0.26 \\
\hline & sICAM-1 year 15 & 520 & 574 & 594 & 617 & 606 & \\
\hline & model 1 & 0 & $-5.9(2.6)$ & $-10.2(2.7)$ & $-14.7(2.8)$ & $-18.5(3.0)$ & $<0.001$ \\
\hline & model 2 & 0 & $-2.2(2.5)$ & $-4.5(2.6)$ & $-5.8(2.8)$ & $-7.5(3.1)$ & 0.02 \\
\hline & model 3 & 0 & $-2.2(2.5)$ & $-4.0(2.6)$ & $-5.3(2.7)$ & $-7.1(3.0)$ & 0.01 \\
\hline & VCAM year 15 & 547 & 609 & 595 & 627 & 620 & \\
\hline & model 1 & 0 & $-19.8(9.9)$ & $-30.7(10.3)$ & $-26.0(10.8)$ & $-25.0(11.6)$ & 0.18 \\
\hline & model 2 & 0 & $-19.7(9.9)$ & $-30.7(10.5)$ & $-26.1(11.2)$ & $-24.8(12.2)$ & 0.25 \\
\hline & model 3 & 0 & $-19.5(10.0)$ & $-30.5(10.5)$ & $-25.8(11.2)$ & $-24.6(12.2)$ & 0.26 \\
\hline & E selectin year 15 & 570 & 594 & 503 & 561 & 461 & \\
\hline & model 1 & 0 & $1.3(1.0)$ & $3.0(1.2)$ & $5.5(1.3)$ & $6.2(1.5)$ & $<0.001$ \\
\hline & model 2 & 0 & $0.2(1.0)$ & $1.5(1.2)$ & $3.6(1.4)$ & $3.9(1.5)$ & $<0.001$ \\
\hline & model 3 & 0 & $0.7(1.0)$ & $1.9(1.2)$ & $3.5(1.3)$ & $3.3(1.5)$ & 0.001 \\
\hline & P selectin year 15 & 600 & 633 & 637 & 693 & 484 & \\
\hline
\end{tabular}




\begin{tabular}{cccccccr}
\hline & & \multicolumn{7}{c}{ Quintile of Dietary Pattern Consumption } & \\
& & $\mathbf{1}$ & $\mathbf{2}$ & $\mathbf{3}$ & $\mathbf{4}$ & $\mathbf{5}$ & Ptrend $^{\boldsymbol{I}}$ \\
\hline model 1 & 0 & $2.4(0.8)$ & $3.8(1.0)$ & $5.3(1.1)$ & $5.7(1.2)$ & $<0.001$ \\
Meat dietary & model 2 & 0 & $1.7(0.8)$ & $2.9(1.0)$ & $3.9(1.1)$ & $4.1(1.2)$ & 0.02 \\
& model 3 & 0 & $1.9(0.8)$ & $3.0(1.0)$ & $3.9(1.1)$ & $3.9(1.2)$ & 0.02 \\
& sICAM-1 year 15 & 599 & 625 & 634 & 581 & 472 & \\
model 1 & 0 & $4.3(3.3)$ & $12.7(3.8)$ & $21.5(4.4)$ & $26.7(4.8)$ & $<0.001$ \\
model 2 & 0 & $-1.9(3.2)$ & $3.9(3.7)$ & $9.0(4.3)$ & $11.9(4.8)$ & 0.02 \\
model 3 & 0 & $-0.5(3.1)$ & $4.9(3.7)$ & $8.5(4.2)$ & $9.8(4.7)$ & 0.04 \\
& VCAM year 15 & 641 & 641 & 635 & 570 & 511 & \\
model 1 & 0 & $10.1(12.2)$ & $-6.8(14.4)$ & $14.8(16.3)$ & $7.3(18.2)$ & 0.73 \\
model 2 & 0 & $10.5(12.3)$ & $-6.5(14.6)$ & $16.2(16.7)$ & $7.3(18.8)$ & 0.67 \\
\hline & model 3 & 0 & $9.9(12.3)$ & $-7.2(14.7)$ & $15.7(16.7)$ & $7.0(18.8)$ & 0.67 \\
\hline
\end{tabular}

sICAM-1 soluble intercellular adhesion molecule 1, VCAM vascular cellular adhesion molecule 1

Model 1: covariates include, race, sex, center, age, energy

Model 2: model 1 plus smoking status, educational attainment and physical activity

Model 3: model 2 plus BMI and waist

${ }^{1}$ P-value for trend based on multivariate adjusted regression analysis with dietary pattern as a continuous value 